\title{
PROCESSO DE DESENVOLVIMENTO DE UM JOGO SÉRIO PARA O ENSINO DAS QUATRO OPERAÇÕES MATEMÁTICAS
}

\author{
Franciely Alves de Souza, Bruno Barboza dos Santos, Maria Renay Barbosa da \\ Silva, Ariane Nunes Rodrigues, Felipe Fernando Barreto. \\ Universidade de Pernambuco, Campus Garanhuns (UPE) \\ CEP 55.294-902 - Garanhuns - PE - Brazil \\ \{francielyalves835, brunobarboza3103, renaybarbosa\}@gmail.com, \\ ariane.rodrigues@upe.br, felipebarreto270yahoo.com.br
}

\begin{abstract}
This article describes the process of developing a Mathematics teaching game containing the contents of the four basic operations. The research highlights the importance of educational games for this context as a way to minimize learning difficulties. The game "Operation Monster" aligns playful aspects to promote learning in a fun way. Designing educational solutions based on learning objectives, in addition to relating special events and design implications in the interface, contribute to the acceptance of serious games.
\end{abstract}

Resumo. Este artigo descreve o processo de desenvolvimento de um jogo para o ensino de Matemática contendo o conteúdo das quatros operações básicas. A pesquisa destaca a importância de jogos educativos para este contexto como forma de minimizar as dificuldades de aprendizagem. $O$ jogo "Operação Monstro" alinha aspectos lúdicos para promover a aprendizagem de forma divertida. Conceber soluções educativas com base em objetivos de aprendizagem, além de relacionar eventos especiais e implicações de design na interface contribuem para aceitação de jogos do tipo sérios.

\section{Introdução}

O uso da tecnologia como ferramenta de aprendizagem está sendo utilizada com mais frequência e de diferentes formas. O uso de jogos digitais, por exemplo, pode ser destacado por manter características próprias e atraentes para crianças e jovens, além de promover uma forma de aprender, diferente do ensino tradicional. Segundo Savi (2008) muitos jovens são seduzidos pelos jogos digitais, permanecem longos períodos totalmente empenhados nos desafios e fantasias. Existem mutuamente vários tipos de jogos que podem ser utilizados a favor da aprendizagem. Os jogos classificados como educativos ou sérios são os mais adequados para contextos educacionais porque mantém aspectos de aprendizagem como principal motivação. Para Silva e Gomes (2015), jogos sérios visam primordialmente objetivos de aprendizagem. Giacomo (2014) destaca que um jogo sério é criado com um propósito que não é apenas diversão. Para Batista (2012), os jogos educativos podem ser utilizados como instrumentos de apoio para a aprendizagem, sendo uma ferramenta de ensino que transforma numa disputa divertida para o caminho do aprender. 
VII Congresso Brasileiro de Informática na Educação (CBIE 2018)

Anais dos Workshops do VII Congresso Brasileiro de Informática na Educação (WCBIE 2018)

Tornar a aprendizagem em um momento divertido como nos jogos não é um processo trivial, principalmente quando o contexto é o ensino da Matemática. Segundo Resende e Mesquita (2013) muitas vezes, ouvem-se declarações de que os estudantes não gostam de matemática, de que a temem e de que a consideram uma disciplina complexa. É necessário compreender como funciona a Matemática porque no Ensino Básico ela ainda é vista como uma disciplina de maior complexidade. A cada ano os alunos possuem dúvidas sobre o conceito e regras das quatros operações e tal fato permite que esse problema seja acompanhado nos anos posteriores. Como Hoffmann et al (2016) afirma não se pode ignorar que o conhecimento é construído de forma colaborativa, valorizando a aprendizagem e a realidade do aluno. No entanto, nem sempre a dificuldade na aprendizagem da matemática se refere aos conteúdos em si, e sim como os conceitos são abordados em sala, quais atividades são utilizadas para fixar o conteúdo, quais metodologias o mediador adota para facilitar a aprendizagem. Ou seja, se trata de um conjunto que se não for observado com cuidado, os alunos passam a ter a aprendizagem comprometida negativamente.

A Matemática é retratada de maneira muito estática, o que causa o não compreendimento do conteúdo por parte de muitos alunos. De acordo com Hoffmann et al (2016). Na utilização de jogos digitais educativos em sala de aula, o papel do professor é o de orientar e incentivar. As atividades apresentadas em sala deveriam trabalhar com a ludicidade como uma maneira de engajar os alunos na aprendizagem. A ludicidade e o engajamento são aspectos de jogos educativos que incentivam o aprendizado indireto como em "aprender jogando". A interação com jogos para este contexto pode dinamizar o processo de aprendizagem como alternativa a resolução de problemas presentes em livros didáticos.

Apesar de existir uma vasta quantidade de softwares educativos para o ensino de matemática, em sua maioria, os softwares do tipo Exercício e Prática são mais comuns. Segundo Silva e Gomes (2015), este tipo de software se assemelha às atividades trazidas em antigos livros didáticos e idealmente deve ser usado quando o aluno tenha conhecimento prévio do assunto em questão. Neste caso, aspectos de imersão ao lúdico são pouco explorados, no sentido de promover prazer ao ato de jogar como influência na aprendizagem.

A ludicidade, como expressão que representa o entretenimento e a diversão em jogos educativos é uma característica que precisa ser mais discutida durante o processo de desenvolvimento de jogos sérios, principalmente para o contexto do ensino de Matemática. De acordo com Pena et al (2013), o lúdico é importante na educação infantil, pois, é através dele que a criança vem a desenvolver habilidades para a aprendizagem se efetivar. Na perspectiva da concepção de jogos, a ludicidade passa a ser interessante, no ponto de vista do usuário, porque trata-se de viver o universo do jogo e não apenas jogá-lo.

Neste contexto, esta pesquisa destaca que os jogos sérios precisam ser concebidos com estratégias lúdicas e implicações de design para que as aprendizagens dos conceitos sejam promovidas de forma divertida. Idealmente, o processo de desenvolvimento de um jogo educativo requer uma equipe multidisciplinar com funções específicas que possam atender os requisitos técnicos e da aprendizagem. Silva e Gomes (2015) destacam o conteudista como especialista da área que domina o assunto do qual se deseja alcançar os objetivos pedagógicos. 
VII Congresso Brasileiro de Informática na Educação (CBIE 2018)

Anais dos Workshops do VII Congresso Brasileiro de Informática na Educação (WCBIE 2018)

Ao considerar todo este contexto, esta pesquisa tem como objetivo apresentar o processo de desenvolvimento de um jogo sério para o contexto do ensino em Matemática, desenvolvido por estudantes de graduação de um curso de Licenciatura em Computação. Esta experiência foi promovida em uma disciplina eletiva, conhecida como Engenharia de Software Educativo, que mantém o objetivo de entender conceitos importantes na área para refletir, avaliar e conceber soluções educativas, inclusive jogos. Neste caso, destaca-se a importância do licenciando em saber planejar um projeto educativo a partir de um problema real, além de gerenciar os recursos humanos e atividades para desenvolver uma solução inovadora que contemple a ludicidade, aprendizagem e interação.

O artigo está estruturado em 6 seções. Além da introdução que apresenta o contexto, a Seção 2 apresenta trabalhos relacionados com destaque para jogos educativos para o ensino de matemática. A Seção 3 detalha o processo de desenvolvimento do jogo educativo para a aprendizagem das operações básicas matemáticas. A Seção 4 destaca detalhes do jogo, como objetivos do jogador e metas a serem cumpridas em cada fase. A Seção 5 detalha os resultados obtidos após a aplicação do jogo. Por fim, a Seção 6 descreve as considerações finais e seguido das referências.

\section{Trabalhos relacionados}

Esta seção apresenta trabalhos que estão relacionados com o contexto deste artigo. Neste caso, são apresentadas pesquisas que destacam uso de jogos educativos para o ensino de matemática, além do desenvolvimento de jogos educativos.

A leitura de trabalhos relacionados é uma atividade importante em uma pesquisa, principalmente quando se refere à concepção de soluções educativas porque promove embasamento teórico ao processo. O estudo de campo descrito por Martins et al (2013) destaca a aplicação de dois objetos de aprendizagem para o ensino de matemática. Foi realizado um levantamento bibliográfico, tendo em vista conhecer alguns jogos sobre o ensino de fração. Um jogo para ensino de fração, chamado de "Arrow Fraction", usa um personagem arqueiro para acertar o número de maçãs, correspondente ao desafio que lhe é mostrado. Já o jogo "Porcento", que mantém o estilo de perguntas e respostas, considera questões sobre frações e que devem ser respondidas em um tempo limitado, pela indicação de opções pré-definidas, não se trata de um jogo lúdico e atrativo. O jogo apresenta uma interface simples, bastante limitada e estática, o usuário não executa nenhuma função a não ser clicar em um botão para marcar a alternativa que deseja.

Em relação a pesquisas que retratam o processo de desenvolvimento de jogos sérios, destaca-se Araújo et. al (2016) por descrever as atividades do processo de desenvolvimento de um jogo focado na conscientização ao combate da dengue. Para os autores, o processo de desenvolvimento deve manter uma relação entre os objetivos pedagógicos, ludicidade e implicações de design. Denominado como "Missão Aedes", o jogo enfatiza a importância em combater a reprodução do mosquito Aedes Aegypti, como causador de várias doenças, além da dengue. O jogo foi desenvolvido para refletir a realidade uma vez que relaciona ações comuns como capturar pneus, vasos e caixas d'água como principais focos de proliferação do mosquito. O jogo também incentiva que o estudante possa analisar a fase de vida do mosquito, assumindo estratégias para prevenir sua evolução e reprodução. 
VII Congresso Brasileiro de Informática na Educação (CBIE 2018)

Anais dos Workshops do VII Congresso Brasileiro de Informática na Educação (WCBIE 2018)

Em Cipriani (2016) é destacado a utilização da tecnologia na educação e descreve a concepção de um jogo sobre a disciplina de matemática. A mecânica do jogo foi desenvolvida baseada nas quatro operações matemáticas fundamentais (adição, subtração, multiplicação e divisão) e consiste na formação de expressões aritméticas simples, que envolvem apenas um operador e dois operandos. $\mathrm{O}$ jogador escolhe um operando, um operador e outro operando, respectivamente. O resultado da expressão formada é então adicionado à pontuação atual do jogador, que inicialmente é zero. $\mathrm{O}$ jogo prossegue até que o jogador atinja a quantidade de pontos determinada pelo objetivo. Percebe-se nesse trabalho, que o intuito é exercitar as operações apenas de forma prática, onde o jogador tem a autonomia de escolher os números para executar a operação e escolher o resultado correto.

Por sua vez, em Filho (2013), é apresentado um jogo educativo de forma lúdica para resolver problemas matemáticos relacionado ao conteúdo de geometria. "As aventuras de Simon Bile" como é chamado tem como personagem principal Simon Bile e seu papel é executar todos os comandos dados pelo jogador no sentido de resolver os problemas presentes no jogo. O Simon é a extensão do processo de raciocínio do jogador. Sobre a jogabilidade, ela pode variar conforme a fase. Na primeira fase o jogador tem uma visão de cima do Simon. Assim a movimentação do personagem ocorre em todas as direções. Já na segunda fase a visão é lateral, como nos jogos de plataforma, assim a movimentação do personagem acontece somente nas laterais, direita e esquerda.

É de extrema importância destacar que, nos trabalhos de Araújo et al, Cipriani e Filho citados nesta seção, é notável perceber que todos os jogos partem da característica educativa, onde os mesmos foram produzidos inteiramente para colaborar com a educação. Ambos se assemelham com o Operação Monstro pelas características lúdicas, interativas e dinâmicas do jogo e pelo seu processo de desenvolvimento.

\section{Processo de desenvolvimento}

Esta seção apresenta detalhes das atividades do processo de desenvolvimento do jogo. Para tal, foram considerados os processos de Jeannie Novak (2010) e Araújo et. al (2016). Como um processo para o desenvolvimento de jogos para iniciantes, o processo de Novak é composto por oito etapas: 1) Conceito; 2) Pré-produção ou planejamento; 3 ) Protótipo; 4) Produção; 5) Alfa; 6) Beta; 7) Ouro e; 8) Pós-produção. Para o desenvolvimento do jogo foram consideradas as seis primeiras etapas, descritas nas próximas seções.

\subsection{Etapas e atividades do processo de desenvolvimento}

Esta seção apresenta as atividades associadas às seis etapas do processo de desenvolvimento. A Tabela 1 apresenta as etapas e suas respectivas atividades.

\begin{tabular}{|c|l|}
\hline Etapas & \multicolumn{1}{|c|}{ Atividades } \\
\hline Conceito & Aplicação: 5W2H e Canvas Game \\
\hline
\end{tabular}


VII Congresso Brasileiro de Informática na Educação (CBIE 2018)

Anais dos Workshops do VII Congresso Brasileiro de Informática na Educação (WCBIE 2018)

\begin{tabular}{|c|l|}
\hline Pré-produção & $\begin{array}{l}\text { Definição da ferramenta construct. } \\
\text { Ludicidade: Definição do universo lúdico a partir do Círculo Mágico; } \\
\text { Definição de habilidades e itens dos personagens; Elementos da Interface } \\
\text { (classificações de efeitos e funções das imagens); Definição dos Processos } \\
\text { cognitivos. }\end{array}$ \\
\hline Protótipo & Desenvolvimento de protótipos funcionais na ferramenta construct 2. \\
\hline Produção & $\begin{array}{l}\text { Desenvolvimento da primeira fase do jogo, com o intuito de receber um } \\
\text { feedback do profissional da área de Matemática com melhorias a essas a } \\
\text { serem implementadas. }\end{array}$ \\
\hline Alfa & Implementação de todas as fases dos jogos. \\
\hline Beta & Realização de melhorias e criação de um manual. \\
\hline
\end{tabular}

Tabela 1. Atividades associadas a cada etapa do desenvolvimento do jogo.

A etapa Conceito representa a fase de elaboração da ideia inicial do jogo. Nesta etapa foram consideradas duas atividades: aplicação da técnica 5W2H e Canvas Game. Como instrumento de gestão, a 5W2H orientou a equipe na definição de um plano de ação sob os questionamentos dos cinco W's e dois H's. Por sua vez, o Canvas Game contribuiu na discussão e definição de elementos essenciais para a concepção do jogo. Aspectos sobre três categorias A, B e C foram consideradas, onde A1 - Público Alvo (crianças de 8 a 12 anos), A2 - Inspirações (Jogos de plataforma), A3 - Objetivo-Enredo (o personagem principal terá que derrotar os monstros resolvendo as operações básicas), A4 - Acessibilidade - Tecnologia (acesso pelo computador), A5 - Quantidade de Jogadores (apenas um jogador); B1 - Personagens de jogador (apenas um personagem principal), B2 - Ações de jogador (andar, correr, abaixar, pular e atacar), B3 - Recursos de jogador (coletar as vidas e utilizar a arma); C1 - Cenários-Janelas (os cenários com climas paisagens variadas), C2 - Desafios (o jogador deverá controlar o personagem para se livrar dos monstros e responder os resultados das operações de forma correta para derrotá-los), C3 - Recompensas (vidas extras contidas em cada fase), C4 Elementos de jogo (quatro tipos de monstros, cada um com sua operação de soma, subtração, multiplicação e divisão), C5 - Fora do Jogo (desafio final tendo um monstro com todas as operações).

Na etapa de Pré-produção, foi definida a ferramenta construct a ser utilizada no desenvolvimento de jogo, por se tratar de um jogo de plataformas a tal ferramenta possui recursos para a implementação. Os detalhes e características do jogo foram melhor definidas, sobretudo quanto ao aspecto da ludicidade. É nesta etapa em que detalhes para os personagens e eventos especiais foram especificados. O conceito do círculo mágico definido por Huizinga (2001), destacado por Mastrocola (2013), destaca a importância em criar uma realidade paralela no jogo (como um círculo imaginário, mágico) com eventos especiais que possam favorecer experiências e significados para a aprendizagem. No jogo, os eventos especiais representam situações de uma forma lúdica, com significados especiais e diferentes do que seria no mundo real. Um exemplo 
VII Congresso Brasileiro de Informática na Educação (CBIE 2018)

Anais dos Workshops do VII Congresso Brasileiro de Informática na Educação (WCBIE 2018)

de evento especial no jogo refere-se ao "efeito gravidade" para permitir que personagem pudesse flutuar e atravessar a porta de acesso a novos estágios.

Os objetivos de aprendizagem foram definidos com base na Taxonomia de Bloom Revisada destacado em Ferraz (2010). Eles relacionam a habilidade (entender, analisar e avaliar) ao conteúdo de matemática, além de especificar como os estudantes irão adquirir o conhecimento. É importante ressaltar que, a participação de um especialista da área de Matemática, contribuiu para a definição de estratégias para a apresentação das operações matemáticas.

Para que a interface do jogo pudesse favorecer a aprendizagem, classificações para imagens, efeitos e implicações de design para ativar processos cognitivos foram considerados. De acordo com Reategui (2007), as imagens usadas em softwares educativos podem ter impacto positivo quando associadas a dois efeitos, o de motivação e o de elaboração.

A elaboração, que tem por objetivo mostrar uma descrição que representam as funcionalidades do jogo, como as imagens das setas de acordo com o teclado para movimentar o personagem. A Motivação do personagem principal, que tem por objetivo realizar uma ação para derrotar os inimigos e não perder vida e motivação que os inimigos despertam, como por exemplo, correr, sobreviver e estratégias de ação.

Já para a representação de imagens, conforme citado em Reategui (2007), foi adotado três tipos: 1) Decorativa, com o propósito de melhorar a aparência estética do jogo (para as imagens das nuvens, água, chuva e neve); 2) Representativa, que exemplifica conceitos apresentados textualmente através da ilustração (história do jogo, ícone de vidas, ícone de moedas); 3) Explanatória, para exemplificar o funcionamento de um sistema dinâmico, considerando o tempo desse funcionamento (para as imagens do personagem, arma e tiros e ícone de ímã e ícone de gravidade).

E por último, nos processos cognitivos de atenção, percepção e memória, foram trabalhadas as características de efeitos visuais, sonoros e ações executadas pelo jogador para vencer os desafios de cada fase. No primeiro é mostrado as ações que causam algum efeito ilustrativo, como podemos ver na Tabela 2.

\begin{tabular}{|c|l|}
\hline Processos Cognitivos & \multicolumn{1}{c|}{ Implicações de Design } \\
\hline $\begin{array}{c}\text { Atenção, Percepção e } \\
\text { Memória }\end{array}$ & $\begin{array}{l}\text { Som emitido sempre que se pega um objeto de efeito especial; } \\
\text { Som emitido de acordo com o ambiente representado no jogo. }\end{array}$ \\
\hline Percepção & Uso de efeito que representa o personagem perdendo vidas; \\
\hline Atenção & $\begin{array}{l}\text { Mensagens representativas que indicam cada vitória ou derrota } \\
\text { conquistada. }\end{array}$ \\
\hline Percepção e Memória & $\begin{array}{l}\text { Uso de imagens representativas destacadas para cada tipo de operação } \\
\text { matemática. }\end{array}$ \\
\hline
\end{tabular}

Tabela 2. Processos Cognitivos e implicações de Design

Na etapa Protótipo, foi realizado uma discussão sobre os protótipos do jogo, e a escolha da ferramenta Construct 2, assim foram elaborados protótipos de acordo com o que a ferramenta Construct 2 disponibiliza de recursos. De acordo com Dias (2018), a 
VII Congresso Brasileiro de Informática na Educação (CBIE 2018)

Anais dos Workshops do VII Congresso Brasileiro de Informática na Educação (WCBIE 2018)

ferramenta Construct 2 é uma game engine (motor de jogo) para a criação de jogos digitais multiplataforma em 2D baseados em HTML 5. Ela permite criar games para smartphones, tablets, computadores, navegadores e também para o console Wii U.

$\mathrm{Na}$ etapa Produção, foi desenvolvido a primeira fase do jogo, que mostrava como seria trabalhada a dinâmica dos problemas a serem solucionados. Após a finalização da primeira fase, foi apresentada a um especialista da área de matemática, onde o mesmo aprovou o projeto e forneceu mais dicas sobre as operações matemáticas dos monstros para a fase inicial e para as próximas fases, bem como a fase final.

$\mathrm{Na}$ etapa Alfa, foi realizado todas as cinco fases do jogo levando em consideração os objetivos e metas que o jogador terá que cumprir, como mostra na Tabela 2, a tela de menu e todos os detalhamentos do tutorial, animações e sons dos efeitos. Nesta etapa, o projeto já se encontra com sua primeira versão finalizada.

Já na etapa Beta, foram realizadas melhorias em algumas fases do jogo como o comprimento do percurso seguido pelo jogador e inseridos mais monstros. Foi produzido um guia de aplicação como um cenário de aprendizagem com dicas para o docente que deseja utilizar o jogo em sala de aula.

A etapa Ouro ainda não foi executada, pois nesta etapa o jogo é disponibilizado para avaliações e após o processo de validação é enviado para plataformas de jogos educativos, assim passando a ser acessível para o público.

\section{O jogo: Operação Monstro}

O jogo "Operação monstro" possui referência em jogos de plataforma, onde o personagem precisa ser movimentado durante todo o percurso do cenário, saltando e correndo evitando obstáculos a partir de comandos executados pelo usuário. $\mathrm{O}$ jogo possui cinco fases e cada uma delas está associada a uma operação matemática (soma, subtração, multiplicação e divisão). O jogador precisa atingir o objetivo de entender o tipo de operação matemática associada a cada fase e cumprir as metas associadas a resolução da operação, além de destruir os monstros pelos recursos oferecidos pelo jogo.

A fase final do jogo é uma junção de todas as quatro operações e tem como intenção de desafiar o jogador a resolver operações matemáticas. A Figura 1 destaca cada fase de jogo através dos protótipos do produto final, pode-se notar que o jogo apresenta as operações devidamente elaboradas na primeira etapa do processo de desenvolvimento.

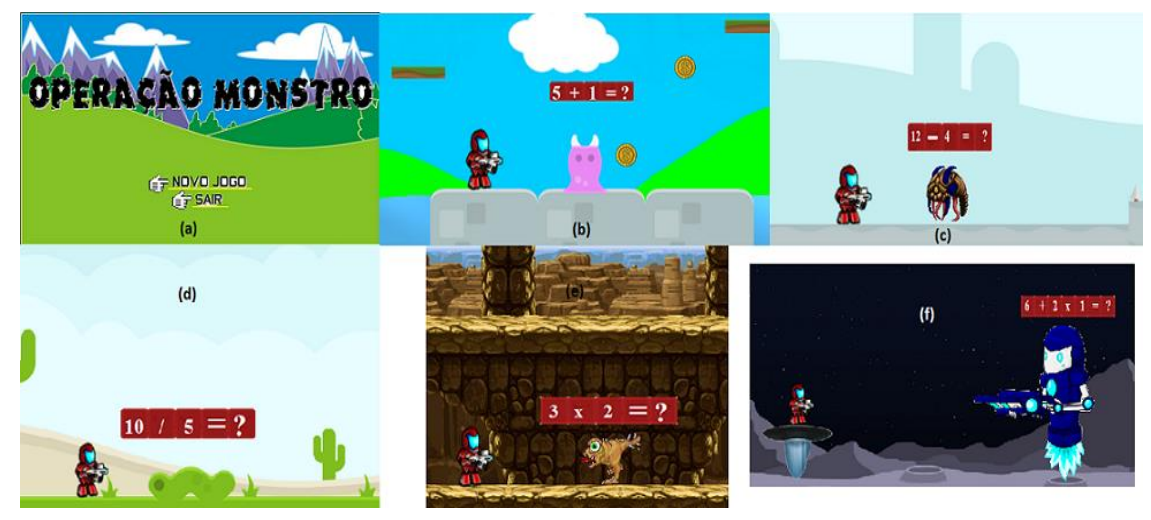

Figura 1. Representação do jogo. 
VII Congresso Brasileiro de Informática na Educação (CBIE 2018)

Anais dos Workshops do VII Congresso Brasileiro de Informática na Educação (WCBIE 2018)

Cada fase do jogo possui diferentes inimigos. Para o cenário foram escolhidos temas que representam a natureza e com eventos climáticos como chuva, deserto, gelo, pedras e por último, o espaço. A escolha de cada cenário foi devidamente pensada no quanto o ambiente poderia prender a atenção do usuário no jogo, sendo possível causar a imersão no círculo mágico.

\section{Resultados}

Para verificar se os objetivos de aprendizagem do jogo foram alcançados com sua aplicação, um questionário de avaliação diagnóstica foi elaborado. O questionário é composto por cinco assertivas que faz referência aos objetivos de aprendizagem, conforme apresenta a Tabela 3.

\begin{tabular}{|l|l|}
\hline \multicolumn{1}{|c|}{ Assertivas Questionário } & \multicolumn{1}{|c|}{ Resultados } \\
\hline $\begin{array}{l}\text { 1. Depois de jogar, consigo diferenciar os sinais associados a cada } \\
\text { operação matemática. }\end{array}$ & $\begin{array}{l}\text { A - Concordo ( 5 ) } \\
\text { B - Indeciso ( 1 ) } \\
\text { C - Discordo ( 0 })\end{array}$ \\
\hline $\begin{array}{l}\text { 2. Após o jogo, consigo responder com facilidade as operações } \\
\text { matemáticas. }\end{array}$ & $\begin{array}{l}\text { A - Concordo ( 5 ) } \\
\text { B - Indeciso ( 1 ) } \\
\text { C - Discordo ( 0 ) }\end{array}$ \\
\hline $\begin{array}{l}\text { 3. Em cada fase consigo entender como resolver cada operação } \\
\text { matemática. }\end{array}$ & $\begin{array}{l}\text { A - Concordo ( 6 ) } \\
\text { B - Indeciso ( 0 ) } \\
\text { C - Discordo ( 0 ) }\end{array}$ \\
\hline $\begin{array}{l}\text { 4. Não tive dificuldades na interação e os movimentos dos personagens. } \\
\text { A - Concordo ( 5 ) } \\
\text { B - Indeciso ( 1 ) } \\
\text { C - Discordo ( 0 ) }\end{array}$ \\
\hline 5. Consegui passar cada fase sem dificuldades. & $\begin{array}{l}\text { A - Concordo ( 4 ) } \\
\text { B - Indeciso ( 1 ) } \\
\text { C - Discordo ( 1 ) }\end{array}$ \\
\hline
\end{tabular}

Tabela 3. Representação dos dados adquiridos com a aplicação do questionário.

As descrições das assertivas refletem aspectos de aprendizagem e são objetivas por considerar a necessidade do público alvo (crianças de 8 a 12 anos) em entendê-las. Em relação à avaliação houve a participação de seis crianças selecionadas de acordo com critérios como: 1) idade; 2) estar cursando os anos iniciais do ensino fundamental II e 3) apresentar dificuldades de aprendizagem nas quatro operações básicas. Este último critério foi identificado durante a seleção antes do processo de interação com o jogo.

Durante a aplicação, as crianças interagiram com o jogo e percebeu-se que cada uma delas levou aproximadamente dez minutos para concluir cada fase. Após a interação com o jogo, o questionário foi aplicado e as crianças deveriam indicar uma opção de resposta (concordo, indeciso e discordo) associada à sua experiência com o jogo. A Tabela 3 indica os valores obtidos para cada assertiva. Para tal, observa-se que o resultado foi satisfatório porque a maioria das respostas se mantive na concordância. A equipe associa este resultado ao fato de que, no jogo, cada operação matemática é tratada de maneira isolada, apresentada em fases diferentes. Esta estratégia foi definida 
VII Congresso Brasileiro de Informática na Educação (CBIE 2018)

Anais dos Workshops do VII Congresso Brasileiro de Informática na Educação (WCBIE 2018)

com o intuito de favorecer o entendimento do conteúdo de forma clara, no sentido de fazer com que o jogador consiga diferenciar as operações.

Apesar do questionário obter dados quantitativos, os resultados para cada assertiva também permitiram observar possíveis dificuldades de interação/usabilidade para que melhorias fossem ser promovidas.

\section{Considerações Finais}

Sabendo das dificuldades existentes com a matemática, apresentadas por alunos de modo geral, a produção de um jogo educativo representando conceitos matemáticos, possui grandes contribuições para o processo de ensino, pois, são projetos dos quais as escolas que podem ser beneficiadas com o acesso a tecnologias que propõe tais ambientes de aprendizagem.

Perante o projeto desenvolvido, usuários que tiveram acesso ao jogo em questão, obtiveram experiências vivenciadas no universo lúdico, e são por meios dessas experiências adquiridas que possuem a oportunidade de buscar novos métodos de aprendizagem com o auxílio da tecnologia, podendo propor tal metodologia para professores que busquem manter a turma engajada no desenvolvimento do conhecimento.

Diante do que foi relatado no decorrer deste artigo, pode-se concluir que como licenciandos foram obtidas diversas experiências, pois, foi com o processo de planejamento desse projeto, que foi possível ocorrer um trabalho em equipe onde cada atividade foi executada de forma sincronizada, identificando erros e planejando o reajuste de cada um deles, a fim de produzir uma aplicação bem elaborada para ser inserida no âmbito escolar. Desta forma proporcionando a inserção da tecnologia como um auxílio no processo de ensino e aprendizagem.

\section{Referências}

CIPRIANI, O.N.(2007).“CONSTRUINDO UM JOGO PARA USO NA EDUCAÇÃO MATEMÁTICA”.

\section{DIAS, Raphael. Construct 2: o Guia Completo.}

FERRAZ, A. P. do C. M.; BELHOT, R. V. Taxonomia de Bloom: revisão teórica e apresentação das adequações do instrumento para definição de objetivos instrucionais. Gest. Prod., São Carlos, v. 17, 2010.

FILHO,P.L.(2013).“JOGO DIGITAL EDUCATIVO PARA O ENSINO DE MATEMÁTICA”.

GIACOMO, (2014, n.p.). Fred Di. Serious Games: como jogos sérios podem ajudar a construir um mundo melhor.

HOFFMANN, L. F.;BARBOSA, D. N.F; DOS SANTOS, P. R. Aprendizagem baseada em jogos digitais educativos para o ensino da matemática - um estudo-piloto a partir da utilização do Erudito. Revista TEKNOS, v.16 n.2, Pag. 38 - 46, (2016).

HUIZINGA, Johan. Homo Ludens. São Paulo: Perspectiva S.A, (2000).

LEAL, Marcel. $\mathbf{O}$ círculo mágico no aprendizado. 
VII Congresso Brasileiro de Informática na Educação (CBIE 2018)

Anais dos Workshops do VII Congresso Brasileiro de Informática na Educação (WCBIE 2018)

MARTINS, F.S.; FERNANDES,M.M.; REBOUÇAS,A.D.D.S.(2015). "Construindo Jogos Digitais para apoiar o Ensino de Matemática e Ensinar a Construir e Testar Sistemas Concorrentes"

Mastrocola, V. M. (2013). "Doses lúdicas: breves textos sobre o universo dos jogos e entretenimento”. / Vicente Martin Mastrocola. - São Paulo: Independente, 2013.

PENA, A.C.; NEVES, M.A.L. (2013). "A importância das atividades lúdicas no universo da educação infantil".

PERIARD, Gustavo.O que é o 5 W2H e como ele é utilizado?

Reategui, E. (2007). "Interfaces para softwares educativos". Revista Novas Tecnologias na Educação.

RESENDE,G.; MESQUITA,M.G.B.F. Principais dificuldades percebidas no processo ensino-aprendizagem de matemática em escolas do município de Divinópolis, MG. Educação Matemática Pesquisa, São Paulo, v.15, n.1, pp. 199-222, (2013).

SAVI, R.; ULBRICHT, V.R.: JOGOS DIGITAIS EDUCACIONAIS: BENEFÍCIOS E DESAFIOS. CINTED-UFRGS: Novas Tecnologias na Educação, Rio Grande do Sul,V. 6 n. 2, (2008).

SEBRAE . CANVAS: Manual Orientativo do Canvas para o Segmento de Games. Brasília, (2014).

SILVA, A. C. B da; GOMES, A. S. Conheça e utilize software educativo: avaliação e planejamento para a educação básica. Série Professor Criativo - Volume 2.

SITE PROATIVA. Objetos de Aprendizagem.

SOUZA, M.M. Ludicidade: da Etimologia da Palavra à Complexidade do Conceito

TOKIO, KAO.8 etapas de criação de games para auxiliar os desenvolvedores iniciantes, por Jeannie Novak. 